\title{
Letter
}

\section{Throwing velocity predictors in elite team handball players}

\author{
ANA ALVES ${ }^{1,2}$, MÁRIO C. MARQUES 1,2 \\ 1 University of Beira Interior, Department of Sport Sciences, UBI, Covilhã, Portugal \\ 2 Research Centre in Sports, Health and Human Development, CIDESD, Vila Real, Portugal
}

\section{DEAR EDITOR-IN- CHIEF}

Team Handball (TH) consists of intense, intermittent activities such as running, sprinting, jumping as well as regular throwing, hitting, blocking, and pushing between players. In addition to technical and tactical skills, it has been argued that one of the key skills necessary for success in team handball is throwing performance (Gorostiaga et al., 2006; Marques and González-Badillo, 2006). Although the technique of motion and the fitness level can be improved by the training process, others variables like strength and power can determine throwing ball velocity (TBv). To our best knowledge, few studies have examined the relationship between ball throwing performance in elite team handball players with dynamic strength and power metrics of the upper-extremity and lower extremities. The bench press is a widely used movement to develop strength and power in the upper-body in TH players. However, data about kinematics factors using light free weights is limited (Gorostiaga et al., 2006). Additionally, others studies observed that TBv is able to establish a strong correlation with lower-extremities, namely with maximum strength and vertical jump (Marques and González-Badillo, 2006). Furthermore, once most throwing actions are made during a step running throw, we also hypostatized that TBv could be related with short srint running. Therefore, aim of this study was to examine the relationship between ball throwing velocity and bench press performance, squat strength, sprint ability, and jump power in a group of elite TH players. A group of fifteen senior elite male TH players volunteered to participate in the study (average age: 23 years-old, range 20-29 years-old), including five Portuguese international players. Subjects were required to sign an informed consent form prior to the study. Study was also approved by the Institutional Review Committee Board of the local Committee for Medical Research Ethics. Study was also developed according to current Portuguese law and regulations as well as, the Helsinki Declaration.

Corresponding author. Universidade da Beira Interior, Departamento de Ciências do Desporto. Rua Marquês d'Ávila e E-mail: mariomarques@mariomarques.com

Submitted for publication December 2012

Accepted for publication September 2013

JOURNAL OF HUMAN SPORT \& EXERCISE ISSN 1988-5202

(c) Faculty of Education. University of Alicante

doi:10.4100/jhse.2013.83.12 
The TBv was evaluated by an over arm throw using a 3-step running throw, which is commonly performed during $\mathrm{TH}$. Players were allowed only a 3-step preparatory run, and were required to release the ball behind the 9 meter line. Each subject performed five throws with a 2 minutes rest between each trial. An average of the four throws with the greatest velocity was used for analysis. The velocity was assessed with a radar gun (Sports Radar 3300, Sports Electronics Inc., USA), with $\pm 0.1 \mathrm{~km} / \mathrm{h}$ accuracy within a field of 10 degrees from the gun.

Dynamic strength was assessed with a 1-repetition concentric only maximal bench press action (1RM) using a free-weight barbell machine. Each player was instructed to perform a concentric only action from this starting position, as quickly as possible, until full extension of the elbows occurred. All players used an initial weight of $25 \mathrm{~kg}$, which was subsequently increased by increments of $10 \mathrm{~kg}, 5 \mathrm{~kg}$ or $2.5 \mathrm{~kg}$ for each trial until an individual could not execute a successful lift. Subjects performed a single repetition at each absolute load, with at least 3 minutes of rest between all trials. The last bearable load was determined as the 1RM. Bar displacement, average velocity $(\mathrm{m} \bullet \mathrm{s}-1)$, and average power $(\mathrm{W})$ were recorded by attaching a rotary encoder to the end of the bar. Customized software (JLML I+D, Madrid, Spain) with an accuracy of $0.0002 \mathrm{~m}$ was used to compute average power for each repetition. It was tested absolute (i.e., $25 \mathrm{~kg}, 35 \mathrm{~kg}$ and $45 \mathrm{~kg}$ ) rather than relative $1 \mathrm{RM}$ loads were used, as reported previously. The absolute loads used represented approximately $33 \%, 47 \%$, and $60 \%$ of the group mean 1RM. Only the first three trials were taken for analysis because power declined significantly $(p=0.022)$ after the third trial $(45 \mathrm{~kg})$.

For sprint testing, subjects were required to perform three maximum effort sprints of 30 metres (S30). Times between 0-15 m (S15), 15-30 m (S15-30) and S30 were recorded using Brower equipment (Wireless Sprint System, USA). Subjects performed trial sprints separated by 3 minutes of rest. Only the average of the best 2 sprints was considered. The countermovement vertical jump height (CMJ) was measured according the test described by Marques and González-Badillo (2006). With a preparatory countermovement, each subject started from an erect standing position and the end of the concentric phase corresponded to a full leg extension (i.e., a $180^{\circ}$ relative angle between limbs). The protocol required the performance of 3 jumps, each followed by 2 minutes of rest. An average of the 2 best jumps was taken to analysis. Subsequently, all performed trials of CMJ weighted with $20 \mathrm{~kg}(\mathrm{CMJ} 20 \mathrm{~kg}), 30 \mathrm{~kg}(\mathrm{CMJ} 30 \mathrm{~kg})$ and $40 \mathrm{~kg}(\mathrm{CMJ} 40 \mathrm{~kg})$ on a shoulder bar. All tests were measured on a trigonometric carpet (Ergojump Digitime 1000, Digest, Finland).

Standard statistical methods were used for the calculation of means and standard deviations of all variables. Differences on each dependent variable between the three absolute loads were determined using a one-way ANOVA with Tukey's post-hoc analysis when appropriate. Correlations were determined using Pearson's r. Statistical significance was accepted at $p \leq 0.05$ for all analysis.

The major findings of this study were the significant correlations between TBv and maximal strength, jump and sprint performances. Although previous studies indicated that $\mathrm{TBv}$ was significant related with distinct kinematics parameters during the concentric bench press, the present research indicated that TBv was only fairly associated with time at maximum rate of force development $(r=0.66 ; p<0.05)$ and rate of force development at peak force $(r=0.566 ; p<0.05)$ with light loads $(25 \mathrm{~kg})$. The analysis of the rate force development during these strength tasks confirmed data already published by others (Wilson et al., 1995). Previous studies also reported several associations between $\mathrm{TBv}$ and indices of upper body strength identical to ours (Marques and González-Badillo, 2006); while others observe few positive associations (van den Tillaar and Ettema, 2007). Nevertheless, few data has been focus on TH players and in this specific throwing task. 
It is quite difficult to compare data about the relationships between TBv and maximal strength in elite $\mathrm{TH}$ players. Studies differ markedly in a number of factors, including the method of measurement of the maximal strength. Another factor that could probably contribute to the different outcomes between previous investigations is the training and playing expertise level of participants.

In this sense, data suggest that 3-step TBv is related to the capacity to move low loads with upper body limbs at maximal velocities. However, these associations were fairly or low, since the overarm throwing kinematic's differs very much from the bench press kinenemtic's. Given the fact that throwing is a highly complex motor skill, it would be unlikely to find a single test that accounts for nearly all of the variability in TBv.

Table 1. Linear relationships between Throwing velocity and distinct measures of bench press strength on linear transducer

\begin{tabular}{|c|c|c|c|c|c|c|}
\hline & $\mathbf{r}$ & & & $p$ value & & \\
\hline & $25 \mathrm{~kg}$ & $35 \mathrm{~kg}$ & $45 \mathrm{~kg}$ & $25 \mathrm{~kg}$ & $35 \mathrm{~kg}$ & $45 \mathrm{~kg}$ \\
\hline $\operatorname{RFD}_{\max .}\left(\mathbf{N} \cdot \mathbf{s}^{-1}\right)$ & Ns & & & $-\overline{---}$ & & \\
\hline Time at RFD $\max (\mathrm{ms})$ & $r=0.571^{*}$ & & & $p=0.042$ & & \\
\hline Force at $\mathrm{RFD}_{\max }(\mathrm{N})$ & Ns & & & --- & & \\
\hline Power at RFD máx. $(\mathrm{W})$ & Ns & & & --- & & \\
\hline Velocity at $\operatorname{RFD}_{\max }\left(\mathrm{m} . \mathrm{s}^{-1}\right)$ & & & $r=0.56^{*}$ & & & $p=0.043$ \\
\hline Displacement at $\mathrm{RFD}_{\max }(\mathrm{m})$ & Ns & & & --- & & \\
\hline$\%$ of PF at $\mathrm{RFD}_{\max }(\mathrm{N})$ & $r=0.613^{*}$ & & & $p=0.026$ & & \\
\hline PF (N) & Ns & & & --- & & \\
\hline Time at PF (m.s-1) & Ns & & & ---- & & \\
\hline RFD at PF $\left(N \cdot s^{-1}\right)$ & Ns & & & --- & & \\
\hline Power at PF (W) & Ns & & & --- & & \\
\hline Velocity at PF (m.s-1) & Ns & & & --- & & \\
\hline
\end{tabular}

\section{REFERENCES}

1. Gorostiaga, E.M., Granados, C., Ibanez, J., Gonzalez-Badillo, J.J. \& Izquierdo, M. (2006). Effects of an entire season on physical fitness changes in elite male handball players. Medicine and Science in Sports and Exercise, 38(2), pp. 357-366.

2. Marques, M.C. \& González-Badillo, J.J. (2006). In-season resistance training and detraining in professional team handball players. Journal of Strength and Conditioning Research, 20(3), pp. 563571. 
3. Marques, M.C., Van den Tillaar, R., Vescovi, J.D. \& González-Badillo, J.J. (2007). Relationship between strength, power, force, and velocity qualities and performance in 3-step running throw ability.. International Journal of Sport Physiology and Performance, 2, pp.414-422.

4. Van den Tillaar, R. \& Ettema, G.A. (2004). A Force-velocity relationship and coordination patterns in overarm throwing. Journal of Sports Sciences and Medicine, 3(4), pp.211-219.

5. Van den Tillaar, R. \& Ettema, G.A. (2007). Three-dimensional analysis of overarm throwing in experienced handball players. Journal of Applied Biomechanics, 23, pp.12-19.

6. Wilson, G.J., Lyttle, A.D., Ostrowski, K.J. \& Murphy, A.J. (1995). Assessing dynamic performances: A comparison of rate force development tests. Journal of Strength and Conditioning Research, 9(3), pp.176-181. 